\title{
Comparison of biochemical failure rates between permanent prostate brachytherapy and radical retropubic prostatectomy as a function of posttherapy PSA nadir plus ' $X$ '
}

\author{
Kamran A Ahmed ${ }^{1}$, Brian J Davis ${ }^{1,2^{*}}$, Lance A Mynderse ${ }^{3}$, Jeffrey M Slezak ${ }^{5}$, Eric J Bergstralh ${ }^{4}$,
}

Torrence M Wilson ${ }^{3}$ and C Richard Choo ${ }^{1}$

\begin{abstract}
Background: Prostate-specific antigen (PSA) nadir $+2 \mathrm{ng} / \mathrm{mL}$, also known as the Phoenix definition, is the definition most commonly used to establish biochemical failure (BF) after external beam radiotherapy for prostate cancer management. The purpose of this study is to compare BF rates between permanent prostate brachytherapy (PPB) and radical retropubic prostatectomy (RRP) as a function of PSA nadir plus varying values of $X$ and examine the associated implications.

Methods and materials: We retrospectively searched for patients who underwent PPB or RRP at our institution between 1998 and 2004. Only primary patients not receiving androgen-deprivation therapy were included in the study. Three RRP patients were matched to each PPB patient on the basis of prognostic factors. BF rates were estimated for PSA nadirs + different values of $X$.

Results: A total of 1,164 patients were used for analysis: 873 in the RRP group and 291 in the PPB group. Patients were equally matched by clinical stage, biopsy Gleason sum, primary Gleason grade, and pretherapy PSA value. Median follow-up was 3.1 years for RRP patients and 3.6 years in the PPB group $(P=.01)$. Using PSA nadir $+0.1 \mathrm{ng} / \mathrm{mL}$ for the definition of BF, the 5 -year BF rate was $16.3 \%$ for PPB patients and $13.5 \%$ for RRP patients $(P=.007)$, whereas at nadir + $2 \mathrm{ng} / \mathrm{mL}$ or greater, the BF rates were less than $3 \%$ and were indistinguishable between PPB and RRP patients.

Conclusions: In a cohort of well-matched patients who had prostatectomy or brachytherapy, we examined BF as a function of nadir $+X$, where $X$ was treated as a continuous variable. As $X$ increases from 0.1 to $2.0 \mathrm{ng} / \mathrm{mL}$, the $B F$ curves converge, and above $2.0 \mathrm{ng} / \mathrm{mL}$ they are essentially indistinguishable. The data presented are of interest as BF definitions continue to evolve.
\end{abstract}

Keywords: Biochemical failure, Brachytherapy, Prostate cancer, Prostatectomy, PSA

\section{Background}

Measuring serum prostate-specific antigen (PSA) is a recommended means for monitoring patients after radiation therapy [1]. A rising PSA level after treatment is frequently associated with subsequent clinical failure. Standardized definitions of biochemical failure (BF) -

\footnotetext{
* Correspondence: davis.brian@mayo.edu

'Department of Radiation Oncology, Mayo Clinic, 200 First St SW, Rochester, MN 55905, USA

${ }^{2}$ Department of Physiology and Biomedical Engineering, Mayo Clinic, Rochester, MN, USA

Full list of author information is available at the end of the article
}

recurrence of PSA after treatment-have been developed to evaluate treatment efficacy and to detect clinical failure.

In 1997, the American Society for Therapeutic Radiology and Oncology (ASTRO) defined BF after external beam radiotherapy (EBRT) as 3 consecutive increases in PSA after treatment; the date of failure is set (backdated) at the midpoint between the time of PSA nadir and the first of the 3 increases [2]. This definition allowed for comparison of outcomes between treatment methods and institutions, but it had limitations. The process of backdating biases the Kaplan-Meier estimates of event-free 
survival and depends on the extent of follow-up [3,4]. The definition, known as the ASTRO definition, also was not optimized with respect to predicting clinical progression, survival, or therapeutic interventions. In 2006, using data from a multi-institutional database of patients treated with EBRT, ASTRO revised the definition of BF to be a PSA value $2 \mathrm{ng} / \mathrm{mL}$ greater than the patient's absolute PSA nadir ("nadir $+2 \mathrm{ng} / \mathrm{mL}$ ") after EBRT [5]. This definition, known as the Phoenix definition, has been shown to have improved sensitivity and specificity in predicting subsequent clinical failure after radiotherapy as compared with the ASTRO definition and many other definitions [6-9]. Another advantage of the new definition is that it tends to limit the number of patients who are designated as having BF because it does not include those who merely experience a benign PSA "bounce" [10,11].

The recommended method of defining BF after radical retropubic prostatectomy (RRP) differs from that after radiation treatment. According to a recommendation by the American Urological Association Prostate Cancer Guideline Panel, the definition of BF after RRP should be an initial PSA level of $0.2 \mathrm{ng} / \mathrm{mL}$ or greater, with a second and identical confirmatory PSA level [12]. Thus, a PSA level above some minimal posttherapy level-nadir for radiotherapy, or undetectable for surgery-has become an important aspect of evaluating patients after both radiation and surgical treatment. However, the magnitude of the PSA value above nadir varies markedly between different therapies.

The purpose of this study was to compare rates of BF between well-matched cohorts of patients with prostate cancer who received two common primary treatment modalities, permanent prostate brachytherapy (PPB) or RRP, as a function of varying PSA nadir plus " $\mathrm{X}$ ". The results may aid in the comparison of different BF definitions across treatment modalities.

\section{Methods and materials}

This study was approved by our institutional review board, and appropriate informed consent was obtained for review of patients' medical records. By searching our prospectively maintained patient databases, we identified all patients who received PPB and RRP at our institution between January 1998 and December 2004. All patients were clinical stage T1c or greater and experienced a decrease in PSA or PSA nadir after primary therapy. The PPB group excluded salvage therapy patients. Prescription doses were consistent with those recommended by the American Brachytherapy Society Guidelines and include patients treated with I- 125 [13]. The RRP group excluded all patients who received neoadjuvant therapy or adjuvant radiation, as well as non-US residents unavailable for regular follow-up. Brachytherapy patients receiving neoadjuvant cytoreductive hormonal therapy were excluded, whereas high risk patients who received neoadjuvant and concomitant androgen deprivation but did not receive adjuvant treatment were included. Three RRP patients were matched to each PPB patient by a computerized matching process [14]. Patients were matched according to Gleason score on biopsy, disease stage, pretreatment PSA value, age, and year of procedure. Patients were followed up postoperatively with serum PSA measurement and digital rectal examination 3 to 4 months after treatment and then every 6 months for the first 5 years and annually thereafter.

Nadir was defined as the lowest PSA value achieved within 3 years of treatment. Subsequent BF was then defined based on PSA nadir plus "X," where X varied from 0.1 to $5.0 \mathrm{ng} / \mathrm{mL}$. BF was also considered to have occurred if there was no posttherapy nadir but the defined PSA increase occurred, if the patient received salvage treatment, or if androgen-deprivation therapy was implemented for an increasing PSA value after therapy.

We evaluated the 5-year Kaplan-Meier estimate of BF based on PSA nadir $+\mathrm{X}$. Continuous variables were summarized as median and range or interquartile range; categorical variables were reported as number (percentage). Associations between continuous variables were assessed by Spearman's correlation analysis. Conditional logistic regression was used to test differences between matched PPB and RRP patients. A 2 -tailed $P<.05$ was considered statistically significant. All statistical analyses were performed using SAS 9.2 and JMP 7 (SAS Institute, Inc).

\section{Results}

\section{Patient characteristics}

A total of 518 patients received $\mathrm{PPB}$ and 5,821 patients received RRP at our institution during the study period. After applying inclusion and exclusion criteria, 1,164 matched patients were evaluated for this analysis: 873 RRP patients and 291 PPB patients. Patient characteristics are summarized in Table 1 . Patients were equally matched by clinical stage $(P=.47)$, biopsy Gleason score $(P=.73)$, primary Gleason grade $(P=.25$, data not shown), and pretherapy PSA value $(P=.95)$. Median age was similar in the PPB and RRP groups (69 vs 68 years; $P=.11$ ). Median follow-up was 3.6 years for RRP patients and 3.1 years in the PPB group $(P=.008)$. Median time to PSA nadir was 3 months after RRP and 2.4 years after PPB (Figure 1).

Brachytherapy implant characteristics for the PPB patients are summarized in Table 2. A total of 273 patients underwent prostate brachytherapy monotherapy and 28 underwent combined treatment with external beam radiotherapy. All twenty patients with Gleason 8 received combined treatment and 8 of 36 patients with Gleason 7 cancer received combined treatment. Of those patients undergoing monotherapy, median prostate volume was $39.7 \mathrm{~mL}$, and 
Table 1 Patient characteristics

\begin{tabular}{|c|c|c|c|}
\hline \multirow[b]{2}{*}{ Characteristic } & \multicolumn{2}{|c|}{ Patient Group } & \multirow[b]{2}{*}{$P$ Value } \\
\hline & PPB $(n=291)$ & $\operatorname{RRP}(n=873)$ & \\
\hline Age, y & & & .11 \\
\hline Median range & $69(41-80)$ & $68(43-80)$ & \\
\hline Mean (SD) & $67.2(6.7)$ & $66.6(6.21)$ & \\
\hline Clinical stage & & & .47 \\
\hline $\mathrm{T} 1$ & $204(70.1 \%)$ & $592(67.8 \%)$ & \\
\hline $\mathrm{T} 2$ & $87(29.9 \%)$ & $281(32.2 \%)$ & \\
\hline Biopsy Gleason score & & & .73 \\
\hline 6 & $235(80.8 \%)$ & $722(82.7 \%)$ & \\
\hline 7 & $36(12.4 \%)$ & $104(11.9 \%)$ & \\
\hline$\geq 8$ & $20(6.8 \%)$ & $47(5.4 \%)$ & \\
\hline Pretherapy PSA value, ng/mL & & & .95 \\
\hline Median (IQR) & $5.7(4.1-7.7)$ & $5.8(4.1-7.6)$ & \\
\hline Range & $0.6-17.5$ & $0.6-23.1$ & \\
\hline Time from therapy to death or last follow-up, y & & & .008 \\
\hline Median & 3.1 & 3.6 & \\
\hline Maximum & 6.9 & 7.5 & \\
\hline Systemic progression & $4(1.4 \%)$ & $4(0.5 \%)$ & .10 \\
\hline Biopsy-proven local recurrence & $1(0.3 \%)$ & $5(0.6 \%)$ & 63 \\
\hline
\end{tabular}

Abbreviations: IQR, interquartile range; PPB, permanent prostate brachytherapy; PSA, prostate-specific antigen; RRP, radical retropubic prostatectomy.

median implanted $\mathrm{mCi}$ was 42.6. Four PPB patients (1.4\%) and 4 RRP patients (0.5\%) had systemic progression $(P=.10)$ (Table 1$)$. There were no differences in local recurrence between the RRP and PPB cohorts: $0.6 \%$ vs $0.3 \%(P=.63)$.

We compared the rates of BF by PSA nadir plus varying values of $\mathrm{X}$ between the RRP and PPB groups (Figure 2). At nadir $+0.1 \mathrm{ng} / \mathrm{mL}$, the 5-year BF estimate (SE) for PPB patients was $16.3 \%$ (2.3\%) and $13.5 \%$ (1.5\%) for RRP patients $(P=.007)$. At nadir $+1.0 \mathrm{ng} / \mathrm{mL}, 5$-year BF was $9.1 \%$

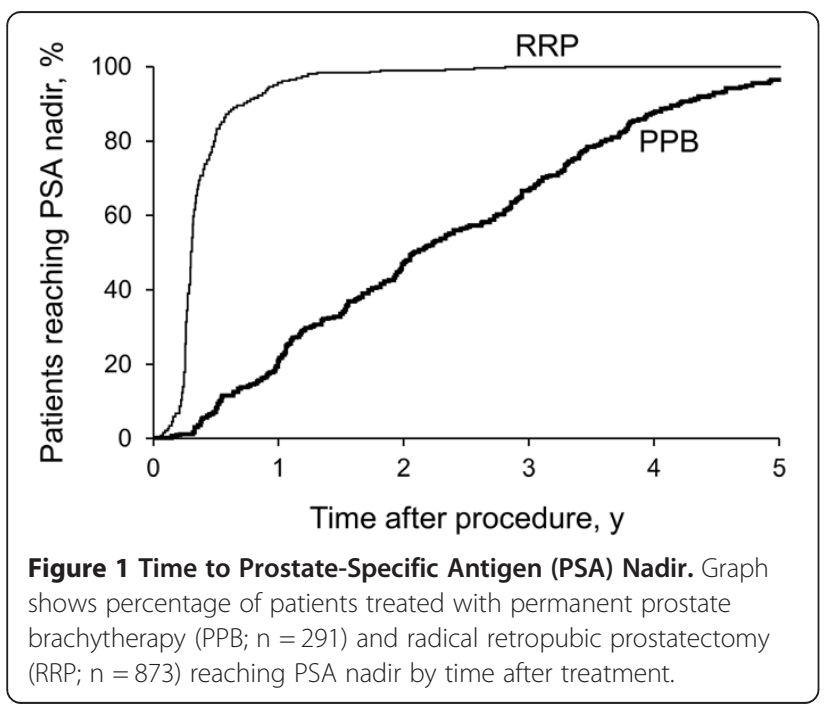

(2.1\%) versus $4.9 \%$ (1.1\%) for the PPB and RRP groups, respectively $(P=.09)$. BF rates were less than $3 \%$ at nadir + $2 \mathrm{ng} / \mathrm{mL}$ or greater and were indistinguishable between $\mathrm{PPB}$ and RRP patients $(P=\mathrm{NS})$. Using two different definitions of BF based on treatment modality, nadir $+2 \mathrm{ng} / \mathrm{mL}$ or greater for $\mathrm{PPB}$ patients and nadir $+0.1 \mathrm{ng} / \mathrm{mL}$ or greater for RRP patients, 5-year BF rates were less than 3\% and $13.5 \%$, respectively.

\section{Discussion}

In this study, we applied the most commonly used and accepted definition of BF in prostate cancer treated with EBRT to a large group of patients treated with PPB or RRP. The patients in the two groups were matched by prognostic factors of Gleason score by biopsy, stage, and PSA value, and year of procedure. We analyzed and compared rates of $\mathrm{BF}$ between patients treated with $\mathrm{PPB}$ and $\mathrm{RRP}$ as a function of a varying PSA nadir plus $\mathrm{X}$. The aims of the study were 1) to examine differences in BF rates in groups of patients with similar prognostic factors and similar clinical outcome with respect to systemic progression, and 2) to provide data to determine if a similar PSA definition for EBRT, brachytherapy, and surgery is tenable. To our knowledge, this is the first study to provide such comparative data and analysis.

Most of the patients in this study had low-risk disease. Studies have demonstrated similar outcomes in biochemical progression-free survival between men treated 
Table 2 Dosimetry characteristics for patients undergoing monotherapy (I-125) in PPB Group $(\mathbf{n}=\mathbf{2 7 3})$

\begin{tabular}{lc}
\hline Characteristic & Median (IQR) \\
\hline Prostate volume, mL & $39.7(31-47)$ \\
mCi implanted & $42.6(36.4-48.2)$ \\
Prostate D90, Gy & $158(146-174)$ \\
Prostate V100,\% & $94.7(90.3-97.8)$ \\
Rectal V100, $\mathrm{mL}$ & $0.28(0.01-1.08)$ \\
\hline
\end{tabular}

Abbreviations: $\mathrm{D} 90$, isodose enclosing $90 \%$ of the prostate; $\mathrm{QR}$, interquartile range; PPB, permanent prostate brachytherapy; $\mathrm{V} 100$, target volume receiving $100 \%$ of the prescribed dose.

with RRP and PPB for low-risk disease [15-17]. A recent study by Arvold et al. [18] of 5,760 men with low-risk prostate cancer and 3,079 men with intermediate-risk prostate cancer found no significant difference in the risk of prostate cancer-specific mortality between these groups after RRP or PPB. In our study, there were no significant differences in systemic progression or biopsyproven local recurrence between patients treated with PPB or RRP.

Although definitions of BF after EBRT have been well studied, these definitions were not intended to be applied to patients treated with PPB or RRP; there is no accepted BF definition that can be applied universally to patients treated with PPB, RRP, and EBRT. For this reason, it is also of interest to examine how definitions of BF compare to one another to better assess outcomes between treatment modalities.

The most commonly used definition of BF after EBRT, the Phoenix definition, evolved from the previous ASTRO definition [2]. Several authors have noted limitations with the ASTRO definition, including not being linked to survival, clinical progression, or interventions $[4,19,20]$. The definition was also very sensitive to follow-up and led to

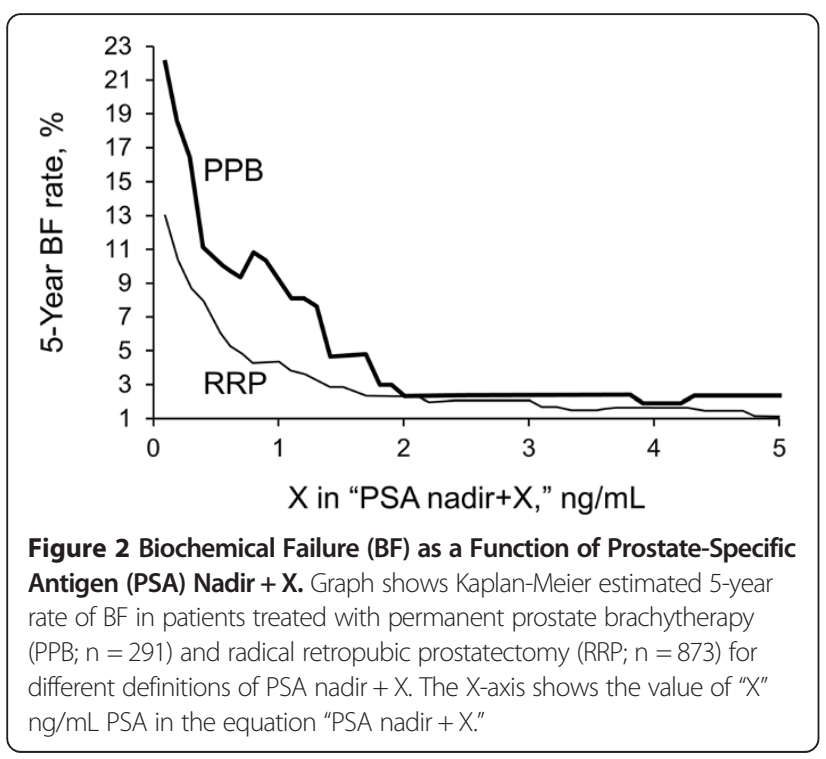

false-positives from benign PSA bounces [10,11]. Several other PSA definitions were suggested, one of which was PSA doubling time as a predictor of failure after EBRT [11,21-23]. In a study of 4,839 patients treated between 1986 and 1995 at 9 academic institutions, Thames et al. [4] found additional definitions to be superior to the ASTRO definition in terms of sensitivity, specificity, positive and negative predictive values, and risk of clinical failure after BF. These definitions included two increases of at least $0.5 \mathrm{ng} / \mathrm{mL}$, PSA level at or greater than the current nadir plus 2 or $3 \mathrm{ng} / \mathrm{mL}$, and PSA level at or greater than the absolute nadir plus $2 \mathrm{ng} / \mathrm{mL}$. The study found the Phoenix definition to have better sensitivity (.67) and specificity (.84) than the ASTRO definition (.61 and .80) for predicting clinical failure.

Since nadir $+2 \mathrm{ng} / \mathrm{mL}$ is the most common definition of BF after EBRT, it is often used in series of patients treated with PPB [24,25]. Kuban et al. [26] analyzed 2,693 patients treated with $\mathrm{PPB}$ and found the nadir $+2 \mathrm{ng} / \mathrm{mL}$ definition to provide the best surrogate for failure throughout the entire follow-up period, similar to patients treated with EBRT. The nadir $+2 \mathrm{ng} / \mathrm{mL}$ definition was more sensitive and specific than PSA doubling time or a certain number of PSA increases. Although the intent of our study was not to propose nadir $+2 \mathrm{ng} / \mathrm{mL}$ as a definition of $\mathrm{BF}$ for both PPB and RRP patients, 5-year BF rates in this study become similar for the two cohorts using a nadir $+2 \mathrm{ng} /$ $\mathrm{mL}$ or greater definition of BF.

After RRP, PSA levels should theoretically become undetectable because the source of PSA, the prostate, is completely excised; therefore, a measureable PSA on follow-up has traditionally been assumed to indicate BF after surgery. Stephenson et al. [27] evaluated 10 definitions of $\mathrm{BF}$ in 3,125 patients who underwent prostatectomy. The study found that a PSA of at least $0.4 \mathrm{ng} / \mathrm{mL}$ followed by another increase best explained metastatic progression. In contrast, the Phoenix definition has not been validated in surgically treated patients and has been found to delay the diagnosis of BF. In a study of 2,570 patients who underwent RRP, Nielsen et al. [28] found that the 5-year biochemical control rates for a definition of nadir $+0.2 \mathrm{ng} / \mathrm{mL}$ or more were similar to the 10 -year biochemical control rates using the nadir $+2 \mathrm{ng} / \mathrm{mL}$ definition. After reviewing the literature from 1991 to early 2004, the American Urological Association recommended using the nadir $+0.2 \mathrm{ng} / \mathrm{mL}$ definition to define BF after surgery [12].

Analyzing $\mathrm{BF}$ as nadir $+\mathrm{X}$ allows $\mathrm{X}$ to be a continuous variable. In the present analysis, as PSA continues to increase above nadir, there is less of a difference in $\mathrm{BF}$ rates between RRP and PPB patients. At the ASTRO definition of nadir $+2 \mathrm{ng} / \mathrm{mL}$, the curves assessing BF between our matched PPB and RRP cohorts become indistinguishable. As PSA continues to increase above nadir, the likelihood 
of biochemical and clinical failure increases, indicating disease progression.

As demonstrated in our study and in the detailed study by Thames et al. [4], there is a fine line in balancing sensitivity and specificity for choosing a definition for BF. If BF is defined as a minimal increase in PSA after nadir, sensitivity of $\mathrm{BF}$ increases. At a low value of $\mathrm{X}$, a larger patient population meets the classification for BF, as noted in Figure 2. By using a minimal increase in PSA after nadir to define $\mathrm{BF}$, emphasis is placed on treatment and better recognition of local recurrence. However, specificity increases when using a larger increase in PSA after nadir to define BF, and the likelihood that these patients had local, regional, or distant failure is increased. Choosing a definition that balances specificity and sensitivity was a question faced by the ASTRO consensus panel when the Phoenix definition was established. In our study, we find similarly indistinguishable outcomes as $\mathrm{X}$ continues to increase above nadir $+2 \mathrm{ng} / \mathrm{mL}$.

Although the study contains a large number of patients it might be expected that a smooth downward trend with increasing values of $X$ would be observed in Figure 2. This is most evident in the PPB curve and the increase between nadir $+0.8 \mathrm{ng} / \mathrm{mL}$ and nadir $+0.9 \mathrm{ng} / \mathrm{mL}$. The number of patients at a given nadir $+\mathrm{X}$ level may vary such that when a failure event occurs, the overall failure rate at a higher nadir $+\mathrm{X}$ may appear greater than for smaller values of $\mathrm{X}$ due to differences in duration of follow up and patients and number censored at a given nadir $+\mathrm{X}$ level. Nevertheless, the general trend downward as $\mathrm{X}$ increases remains evident and is consistent with prior studies analyzing PSA failure and EBRT [Thames].

Our study had several limitations. First, our analysis is subject to many of the limitations common to retrospective analyses. It is also a single-institution study, which may introduce selection bias. Although our cohorts of PPB and RRP patients were well matched, some statistical differences were noted in length of maximum follow-up. Because surgical treatment is relatively more established in our institution compared with brachytherapy, the RRP group had a longer follow-up period at the time of analysis. However, this is unlikely to have affected our analysis of BF between the two techniques. In addition, although we observed no significant differences in systemic progression between the two cohorts, the small number of total events $(n=8)$ limits the power for such comparisons and the ability to link nadir $+\mathrm{X}$ with later clinical events.

\section{Conclusion}

In a cohort of well-matched patients who underwent either RRP or PPB and had similar local recurrence and systemic failure rates, we examined $\mathrm{BF}$ as a function of PSA nadir $+X$, where $X$ was treated as a continuous variable. As $\mathrm{X}$ increases from 0.1 to $2.0 \mathrm{ng} / \mathrm{mL}$, the 5 -year Kaplan-Meier BF estimate curves for the two groups converge, and above $2.0 \mathrm{ng} / \mathrm{mL}$ they are essentially indistinguishable. These data and analysis are of interest in examining means by which to compare biochemical failure between differing treatment modalities.

\section{Competing interests}

The authors declare that they have no competing interests.

\section{Authors' contributions}

KAA carried out the design of the study, data retrieval, statistical analysis, and drafted the manuscript. CAM, EJB, TMN, CRC carried out a critical review of the manuscript. JMS carried out statistical analysis of the manuscript. BJD conceived of the study, and participated in its design and coordination. All authors read and approved the final manuscript.

\section{Acknowledgments}

Portions of this work were funded by the National Cancer Institute grant, P50 CA 91956.

\section{Author details}

'Department of Radiation Oncology, Mayo Clinic, 200 First St SW, Rochester, MN 55905, USA. ²Department of Physiology and Biomedical Engineering, Mayo Clinic, Rochester, MN, USA. ${ }^{3}$ Department of Urology, Mayo Clinic, Rochester, MN, USA. ${ }^{4}$ Division of Biomedical Statistics and Informatics, Mayo Clinic, Rochester, MN, USA. ${ }^{5}$ Department of Research and Evaluation, Kaiser Permanente Southern California, Pasadena, California.

Received: 11 May 2014 Accepted: 25 July 2014

Published: 29 July 2014

\section{References}

1. Mclntosh HM, Neal RD, Rose P, Watson E, Wilkinson C, Weller D, Campbell C: Prostate Cancer Follow-up Group. Follow-up care for men with prostate cancer and the role of primary care: a systematic review of international guidelines. Br J Cancer 2009, 100(12):1852-1860. Epub 2009 May 12.

2. American Society for Therapeutic Radiology and Oncology Consensus Panel: Consensus statement: guidelines for PSA following radiation therapy. Int J Radiat Oncol Biol Phys 1997, 37(5):1035-1041.

3. Vicini FA, Kestin LL, Martinez AA: The importance of adequate follow-up in defining treatment success after external beam irradiation for prostate cancer. Int J Radiat Oncol Biol Phys 1999, 45(3):553-561.

4. Thames H, Kuban D, Levy L, Horwitz EM, Kupelian P, Martinez A, Michalski J, Pisansky T, Sandler H, Shipley W, Zelefsky M, Zietman A: Comparison of alternative biochemical failure definitions based on clinical outcome in 4839 prostate cancer patients treated by external beam radiotherapy between 1986 and 1995. Int J Radiat Oncol Biol Phys 2003, 57(4):929-943.

5. Roach M 3rd, Hanks G, Thames H Jr, Schellhammer P, Shipley WU, Sokol GH, Sandler $\mathrm{H}$ : Defining biochemical failure following radiotherapy with or without hormonal therapy in men with clinically localized prostate cancer: recommendations of the RTOG-ASTRO Phoenix Consensus Conference. Int J Radiat Oncol Biol Phys 2006, 65(4):965-974.

6. Thompson A, Keyes M, Pickles T, Palma D, Moravan V, Spadinger I, Lapointe $\checkmark$, Morris WJ: Evaluating the Phoenix definition of biochemical failure after (125)I prostate brachytherapy: can PSA kinetics distinguish PSA failures from PSA bounces? Int J Radiat Oncol Biol Phys 2010, 78(2):415-421. Epub 2010 Feb 3.

7. Stephenson AJ: Is the Phoenix definition superior to ASTRO for predicting clinical outcomes in prostate cancer? Nat Clin Pract Urol 2008, 5(7):356-357. Epub 2008 May 20.

8. Bellera CA, Hanley JA, Joseph L, Albertsen PC: A statistical evaluation of rules for biochemical failure after radiotherapy in men treated for prostate cancer. Int J Radiat Oncol Biol Phys 2009, 75(5):1357-1363. Epub 2009 Apr 22.

9. Abramowitz MC, Li T, Buyyounouski MK, Ross E, Uzzo RG, Pollack A, Horwitz EM: The Phoenix definition of biochemical failure predicts for overall survival in patients with prostate cancer. Cancer 2008, 112(1):55-60. 
10. Zietman AL, Christodouleas JP, Shipley WU: PSA bounces after neoadjuvant androgen deprivation and external beam radiation: impact on definitions of failure. Int J Radiat Oncol Biol Phys 2005, 62(3):714-718.

11. Stock RG, Stone NN, Cesaretti JA: Prostate-specific antigen bounce after prostate seed implantation for localized prostate cancer: descriptions and implications. Int J Radiat Oncol Biol Phys 2003, 56(2):448-453.

12. Cookson MS, Aus G, Burnett AL, Canby-Hagino ED, D'Amico AV, Dmochowski RR, Eton DT, Forman JD, Goldenberg SL, Hernandez J, Higano CS, Kraus SR, Moul JW, Tangen C, Thrasher JB, Thompson I: Variation in the definition of biochemical recurrence in patients treated for localized prostate cancer: the American Urological Association Prostate Guidelines for Localized Prostate Cancer Update Panel report and recommendations for a standard in the reporting of surgical outcomes. J Urol 2007 177(2):540-545.

13. Davis BJ, Horwitz EM, Lee WR, Crook JM, Stock RG, Merrick GS, Butler WM, Grimm PD, Stone NN, Potters L, Zietman A, Zelefsky MJ: American Brachytherapy Society consensus guidelines for transrectal ultrasoundguided permanent prostate brachytherapy. Brachytherapy 2012, 11(1):6-19.

14. Bergstralh EJ, Kosanke $J$, Jacobsen SJ: Software for optimal matching in observational studies. Epidemiology 1996, 7(3):331-332.

15. D'Amico AV, Whittington R, Malkowicz SB, Schultz D, Blank K, Broderick GA Tomaszewski JE, Renshaw AA, Kaplan I, beard CJ, Wein A: Biochemical outcome after radical prostatectomy, external beam radiation therapy, or interstitial radiation therapy for clinically localized prostate cancer. JAMA 1998, 280(11):969-974.

16. Zelefsky MJ, Kuban DA, Levy LB, Potters L, Beyer DC, Blasko JC, Moran BJ, Ciezki JP, Zietman AL, Pisansky TM, Eishaikh M, Horwitz EM: Multiinstitutional analysis of long-term outcome for stages T1-T2 prostate cancer treated with permanent seed implantation. Int I Radiat Oncol Biol Phys 2007, 67(2):327-333. Epub 2006 Nov 2.

17. Giberti C, Chiono L, Gallo F, Schenone M, Gastaldi E: Radical retropubic prostatectomy versus brachytherapy for low-risk prostatic cancer: a prospective study. World J Urol 2009, 27(5):607-612. Epub 2009 May 20

18. Arvold ND, Chen MH, Moul JW, Moran BJ, Dosoretz DE, Banez LL, Katin MJ, Braccioforte $\mathrm{MH}, \mathrm{D}^{\prime}$ Amico $\mathrm{AV}$ : Risk of death from prostate cancer after radical prostatectomy or brachytherapy in men with low or intermediate risk disease. J Urol 2011, 186(1):91-96. Epub 2011 May 14

19. Pickles T, Duncan GG, Kim-sing C, McKenzie MR, Morris WJ: PSA relapse definitions: the Vancouver Rules show superior predictive power. Int J Radiat Oncol Biol Phys 1999, 43(3):699-700.

20. Kestin LL, Vicini FA, Martinez AA: Practical application of biochemical failure definitions: what to do and when to do it. Int J Radiat Oncol Biol Phys 2002, 53(2):304-315

21. Taylor JM, Yu M, Sandler HM: Individualized predictions of disease progression following radiation therapy for prostate cancer. $J$ Clin Oncol 2005, 23(4):816-825.

22. D'Amico AV, Whittington R, Malkowicz SB, Fondurulia J, Chen MH, Kaplan I, Beard CJ, Tomaszewski JE, Renshaw AA, Wein A, Coleman CN: Pretreatment nomogram for prostate-specific antigen recurrence after radical prostatectomy or external-beam radiation therapy for clinically localized prostate cancer. J Clin Oncol 1999, 17(1):168-172.

23. Sartor $\mathrm{Cl}$, Strawderman $\mathrm{MH}$, Lin XH, Kish KE, McLaughlin PW, Sandler HM: Rate of PSA rise predicts metastatic versus local recurrence after definitive radiotherapy. Int J Radiat Oncol Biol Phys 1997, 38(5):941-947.

24. Stone NN, Potters L, Davis BJ, Ciezki JP, Zelefsky MJ, Roach M, Shinohara K, Fearn PA, Kattan MW, Stock RG: Multicenter analysis of effect of high biologic effective dose on biochemical failure and survival outcomes in patients with Gleason score 7-10 prostate cancer treated with permanent prostate brachytherapy. Int J Radiat Oncol Biol Phys 2009, 73(2):341-346. Epub 2008 Jul 1

25. Gomez-Iturriaga Pina A, Crook J, Borg J, Ma C: Biochemical disease-free rate and toxicity for men treated with iodine-125 prostate brachytherapy with $\mathrm{d}(90) \geq 180 \mathrm{~Gy}$. Int J Radiat Oncol Biol Phys 2010, 78(2):422-427.

26. Kuban DA, Levy LB, Potters L, Beyer DC, Blasko JC, Moran BJ, Ciezki JP, Zietman AL, Zelefsky MJ, Pisansky TM, Elshaikh M, Horwitz EM: Comparison of biochemical failure definitions for permanent prostate brachytherapy. Int J Radiat Oncol Biol Phys 2006, 65(5):1487-1493. Epub 2006 Jun 5.
27. Stephenson AJ, Kattan MW, Eastham JA, Dotan ZA, Bianco FJ Jr, Lilja H, Scardino PT: Defining biochemical recurrence of prostate cancer after radical prostatectomy: a proposal for a standardized definition. J Clin Oncol 2006, 24(24):3973-3978.

28. Nielsen ME, Makarov DV, Humphreys E, Mangold L, Partin AW, Walsh PC: Is it possible to compare PSA recurrence-free survival after surgery and radiotherapy using revised ASTRO criterion: "nadir + 2"? Urology 2008, 72(2):389-393. Epub 2008 Feb 15.

doi:10.1186/1748-717X-9-171

Cite this article as: Ahmed et al:: Comparison of biochemical failure rates between permanent prostate brachytherapy and radical retropubic prostatectomy as a function of posttherapy PSA nadir plus 'X'. Radiation Oncology 2014 9:171.

\section{Submit your next manuscript to BioMed Central and take full advantage of:}

- Convenient online submission

- Thorough peer review

- No space constraints or color figure charges

- Immediate publication on acceptance

- Inclusion in PubMed, CAS, Scopus and Google Scholar

- Research which is freely available for redistribution

Submit your manuscript at www.biomedcentral.com/submit
C BioMed Central 